\title{
FULL-SCALE UPPER-SURFACE-BLOWN FLAP NOISE
}

by L.J. Heidelberg, L. Homyak and W. L. Jones

Lewis Research Center

Cleveland, Ohio 44135

TECHNICAL PAPER to be presented at National Air Transportation Meeting sponsored by the Society of Automotive Engineers Hartford, Connecticut, May 6-8, 1975

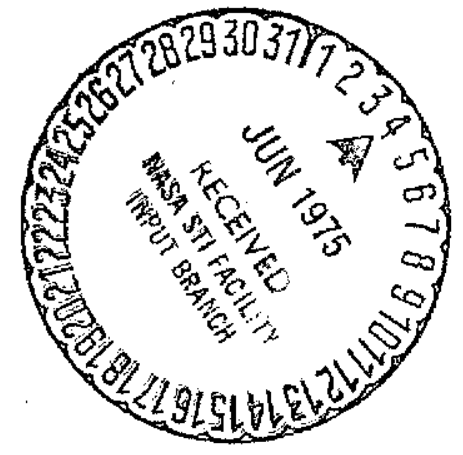


FULL-SCALE UPPER-SURFACE-BLOWN FLAP NOISE

by L. J. Heidelberg, L. Homyak, and $W$. L. Jones

Lewis Research Center

National Aeronautics and Space Administration

Cleveland, Ohio

ABSTRACT

A highly noise suppressed TF 34 engine was used to investigate the noise of several powered lift configurations involving upper-surface-blown (USB) flaps. The configuration variables were nozzle type (i.e. slot and circular with deflector), flap chord length, and flap angle. The results of velocity surveys at both the nozzle exit and the flap trailing edge are also presented and used for correlation of the noise data. Configurations using a long flap design were $4 \mathrm{~dB}$ quieter than a short flap typical of current trends in USB flap design. The lower notse for the long flap is attributed primarily to the greater velocity decay of the jet at the flap trailing edge. The full-scale data revealed substantially more quadrupole $\left(V^{8}\right)$ noise in the region near the deflected jet than observed in previous sub-scale tests.

\section{INTRODUCTION}

Short takeoff and landing (STOL) alrcraft are being, considered for future short-haul air transportation systems. Such aircraft would likely have to operate out of many small airports close to populated areas. For this reason, these aircraft would have to be considerably more quiet than conventional aircraft. To achieve the desired STOL flight characteristics, powered lift must be used. Unfortunately, there are additional noise sources associated with powered lift systems that are a result of the interaction of the jet exhaust with the wing and flaps. These additional noise sources can dominate the system noise. One of the most promising of the powered lift systems being considered for short-haul STOL afrcraft is the upper-surface-blown (USB) flap. A major advantage of the USB system is the acoustic shielding provided by the wing in the region below the aircraft.

The noise generated by a USB system has been investigated in sub-scale model tests (refs. 1-3) and to a very limited extent with a turbofan engine in full-scale (refs. 4-6). A series of acoustic tests investigating 
USB flap systems using a full-scale engine and wing was conducted at NASA Lewis Research Center. This test series is part of a program using a highly noise suppressed TF 34 engine in an acoustic investigation of externally blown flap systems. The TF 34 engine was used in this program because of its high bypass ratio $(6.5: 1)$ and relatively low fan and core exit velocities.

The objective of the USB flap test series was to generate full-scale noise data for several nozzle and flap configurations. More specifically, the objectives were: (1) to determine the effect of nozzle type (slot and circular with external deflector) on overall system noise; and (2) to determine the effect of flap geometry (chord length and angle) on noise.

To accomplish the above objectives, noise and aerodynamic measurements were taken for both a slot and a circular nozzle with long and short chord flap systems. The slot nozzle was also tested with $8^{\circ}, 40^{\circ}$, and $75^{\circ}$ flap angles, using the short flaps. Extensive velocity surveys were performed at the slot nozzle exit and at the flap trailing edge. A velocity profile was measured ten feet downstream of the flaps in order to obtain an indication of flow turning angle.

The results of these tests are presented in this paper. A comparison of test results with existing noise predictions for USB flaps is made. Attempts to correlate the noise with both engine exhaust velocity and flap trailing edge velocity are also made.

\section{APPARATUS AND PROCEDURE}

\section{Engine}

The TF 34 turbofan engine is a dua1-rotor front-fan configuration having a nominal bypass ratio of 6.5 . It has a single-stage fan with a tip diameter of 44 inches and a pressure ratio of 1.5 . The core compressor is a 14-stage axial-flow machine with variable stators and nominal pressure ratio of 14.5 . The gas generator high pressure turbine has two axial stages, both air-cooled. The fan low pressure turbine has four axial-flow stages and drives the fan through a concentric shaft passing forward inside the gas generator rotor. Air is introduced directly to the fan rotor with no fan inlet guide vanes. A noise suppressed engine installation having a mixed-flow exhaust configuration was used for this investigation. Some of the performance characteristics of both the unsuppressed and the suppressed engine configurations are given in Table $I$. 
Nacelle

The acoustically treated ground test nacelle used in this test series is schematically shown in figure 1. A circular nozzle is shown here installed on the engine. A very conservative philosophy was used in designing the suppression to Insure that fan and core noise would be kept below the jet noise floor. The nacelle accomplishes this goal at angles greater than $50^{\circ}$ from the inlet. This makes the engine and nacelle an ideal tool for investigating flap noise in full-scale. The test nacelle is comprised of three major components: inlet suppressor; aft fan suppressor; and core suppressor. Reference 7 provides a description of the nacelle and its design goals. Although the acoustic and aerodynamic performance of the nacelle have been reported in references 5 and 7 , a brief description of the nacelle is provided here as a convenience.

The inlet suppressor consists of a treated outer wall about 1.5 diameters in length with three acoustically treated splitter rings. The treatment is of the honeycomb type. A bellmouth is fitted to the forward end of the inlet suppressor. The aft fan suppressor consists of an acoustically-treated inner and outer wall. The treatment used here is a bulk absorber type. The shape of the flow passage is such that almost no line of sight exists between the fan and the suppressor exit. The core suppressor provides both high frequency treatment for turbine noise and low frequency treatment for combustor noise. Both inner and outer walls make use of bulk absorber type treatment.

Nozzles

Both a canted slot nozzle and a circular nozzle with external deflector were used in this investigation. Photographs of the two exhaust nozzles on test with a wing section are shown in figures $2(a)$ and $2(b)$. Both exhaust nozzles were tested with an engine configuration utilizing an internal core mixer nozzle as shown in figure 1. This mixer nozzle mounts on the exit of the core suppressor and provides internal mixing of the core and fan streams. The core nozzle makes a smooth transition from a $280 \mathrm{in}^{2}$ annular passage to 12 symmetric lobes around a centerbody with an exit flow area of $251 \mathrm{in}^{2}$. Some test results for this 12 lobe daisy-type internal mixer with a circular exhaust nozzle are presented in reference 4.

Slot nozzle. - This nozzle has a rectangular exit with an aspect ratio of $4: \overline{1}$. Figure 3 shows two views of the nozzle with a section of the wing. The $4: 1$ aspect ratio was chosen on the basis of a compromise between internal performance, external drag, and jet attachment to the flap. Increasing the aspect ratio reduces the jet thickness over the flap. A small jet 
thickness relative to the flap radius is desirable for Coanda type turning. However, increasing the nozzle aspect ratio also results in increasing penalties in the form of internal flow losses and external drag. The nozzle was designed to provide adequate flow attachment to the flaps for an approach as well as a takeoff flap setting.

The nozzle mates to the exhaust duct at the point of confluency between the core and fan streams. From this point, the circular cross sec tion undergoes a transition to rectangular cross section through a series of rectangles of decreasing corner radius. The flow exits the nozzle and impinges on the wing at a high angle. The nozzle turns the flow $20^{\circ}$ from the engine centerline while the engine centerline is inclined $2.5^{\circ}$ above the wing chord line ( $f i g .3$ ). The high impingement angle induces flow spreading for better flow attachment. The nozzle exit area was sized to produce an efficient fan operating line and engine cycle. Flexible leaf seals on the nozzle floor provide a smooth transition to the wing surface.

Circular nozzle and deflector. - As shown in figure 4, this nozzle is a simple convergent design with a circular cross section. It has a cone half angle of about $5^{\circ}$ and an exit diameter of 35.1 in. The exhaust jet is deflected by a flat steel plate 12 inches downstream of the nozzle exit. The deflector plate is hinged so that the deflector angle $\delta_{\mathrm{d}}$ is adjustable. This plate has a width of 42 in and a length of 27 in. The nozzle exit is less than one inch above the wing surface.

Wings

Two wings were used in this investigation and are shown in figure 5. One is an unswept wing of constant chord with a relatively short flap. The other is a swept and tapered wing with a long flap. Both wings (with retracted flaps) have the same chord length at the engine centerline station. The flaps for both wings have a single constant radius surface with no slots. The location of the nozzle exit was at 25 percent of the wing chord for all configurations.

Unswept wing (short flap). - The airfoil contour and flap geometry of this wing are representative of current USB STOL aircraft concepts. This wing is unswept and has a constant chord. The airfoil contour used is the NASA 23012 series scaled up to a four-engine TF 34-powered aircraft wing size. Relatively small flap radius-to-chord ratios were used for this flap system as shown in figure 5(a). The flaps are identified by flap angle $\delta_{f}$. In this paper, $\delta_{f}$ will be defined as the angle between the chord line and a line tangent to the upper surface of the flap at the trailing edge. Three flap attachments can be fitted to this wing; $8^{\circ}$ flap (retracted flap), $40^{\circ}$ flap (takeoff) and $75^{\circ} \mathrm{flap}$ (approach). 
Swept wing. - The swept and tapered wing section was originally built to test under-the-wing blown flap systems with the TF 34 engine. It has been described in reference 4 . Figure $5(\mathrm{~b})$ gives the important dimensions for the modified wing used in this investigation. The original tripleslotted flaps were replaced with a large constant-radius USB flap. This flap approximates the upper surface contour of the triple-slotted flaps at the engine centerline station for the takeoff $40^{\circ}$ flap angle. This was the only flap available for testing with the swept wing. An extension was added to the outer span of the wing to provide more realistic noise shielding.

\author{
Test Facility
}

Tests were performed at a relatively new outdoor facility at the Lewis Research Center. This facility is capable of both noise and performance testing of powered lift systems. The engine is hung from an overhead thrust frame which in turn is supported by a cantilevered structure. Figure 6 is a photograph of the engine and swept wing in position at the test facility. The thrust frame and engine are pivoted to allow rotation in a horizontal plane of $180^{\circ}$. The engine centerline is 9 feet above the ground. The wing is mounted vertically on a movable table. The combination of wing and engine movements provide the flexibility needed to test many different powered lift configurations. A flat semicircular area of over 100 feet in radius is paved from the wing to beyond the microphones.

\title{
Instrumentation
}

Acoustic instrumentation, - Far-field acoustic measurements were made with two microphone arrays: the ground array, and the boom array. The ground microphone array consists of $\frac{1}{2}$-inch condenser-type microphones mounted horizontally on thin flat plates at ground level. These microphones are arranged at $10^{\circ}$ intervals from $30^{\circ}$ to $130^{\circ}$ from the inlet on a 100-foot radius centered on the exhaust nozzle exit. Since the wing is mounted vertically, this array provides data that can be projected to various distances in the flyover plane.

The boom microphone array shown in position in figure 6 provides data that can be projected to a 500-foot sideline for various simulated aircraft altitudes. A large crane was used to hoist the boom array into position. The boom array consists of microphones mounted on a cross-like structure with the long arm in a plane perpendicular to the engine axis. The microphones on the long arm are positioned so as to provide data at the following altitudes when projected on a 500-foot sideline: 0 (directly over the 
wing tip), 100,250 , and 400 feet. The short arm provides data at 250 feet altitude at angles on either side of $90^{\circ}$ from the inlet. These microphones are all at distances of over 60 feet from the nozzle.

Aerodynamic instrumentation. - Extensive pressure and temperature instrumentation on the engine were used to determine the engine operating characteristics. Reference 4 provides a more detailed description of the internal engine instrumentation.

The locations at which flow surveys were performed with a traversing probe and the location of a large fixed survey rake are shown in figure 7 . The traversing probe measures total pressure and temperature and was used to map the flow at the nozzle exit and at the flap trailing edge. Velocities were calculated from these measurements. The probe was capable of traversing in two mutually perpendicular directions. This feature reduced the time required to map a large complex flow. A large survey rake with 85 elements spaced at one-inch intervals was used to provide flow turning angle information. Static pressure elements alternate with dual total pressure and temperature elements on this rake. The rake was positioned about 10 feet downstream of the flap tralling edge so as to span the deflected jet.

Test procedure

Two different types of tests were run. The aerodynamic tests utilized complete engine internal instrumentation and external flow survey probes. Acoustic tests were run with no external flow rakes or probes and no engine inlet or fan stream rakes. This eliminates the possibility of instrumentation-generated noise from contaminating the noise measurements. Data were only taken when the wind speed was under $10 \mathrm{mph}$. Generally, data were taken for six power settings ranging between maximum power and a low power setting corresponding to a fan speed of 4,000 rpm.

For configurations involving the circular nozzle and deflector, the aerodynamic tests were run first. These tests were always started with the deflector angle being increased until satisfactory flow attachment to the flap was obtained. The traversing probe located at the flap trailing edge at engine centerline height was used to determine flow attachment. If the peak velocity at this location was no more than 3 inches from the flap surface, the flow was considered attached. Time did not permit a more complete flow attachment criterion. The deflector angle $\delta_{\mathrm{d}}$ used with the unswept wing (short flap) was $30^{\circ}$ and $27.5^{\circ}$ with the swept wing (long flap). 


\section{Calculation Procedures}

All acoustic data were analyzed on-line with a one-third octave band analyzer. The resulting sound pressure levels in units of $d B$ are referenced to 0.0002 microbar. All further processing of the data were done on a digital computer.

Data from the ground microphone array were corrected to free-field conditions by subtracting $6 \mathrm{~dB}$ at all frequencies up to $20,000 \mathrm{~Hz}$. This correction accounts for the effect of the part of the signal that is reflected from the ground. This $6 \mathrm{~dB}$ value is indicated by theory for a perfectly reflecting surface and has been checked by tests at this facility and found to be adequate. The maximum possible error for the boom array due to ground reflections was estimated to be $1.8 \mathrm{~dB}$. Consequently, no corrections for ground reflections were deemed necessary. All data reported in this paper were corrected to an atmospheric temperature of $77^{\circ} \mathrm{F}$ and a relative humidity of 70 percent.

The exhaust jet velocity for the slot nozzle was determined from measurements taken with a traversing total pressure and temperature probe in the nozzle exit plane (fig. 7). Fully expanded velocities were calculated from the total stream conditions by assuming an isentropic expansion to ambient pressure. These velocities were then mass averaged across the exit plane to arrive at a $v_{j}$. It is this average velocity that is used as a correlating parameter in this paper.

The large survey rake shown in figure 7 was used to determine the flow turning angle of the flap. The velocity profile along the rake was calculated using the isentropic relationships. The center of momentum of the flow was calculated for this profile. The flow angle was then determined by extending a line back to the center of flow at the flap trailing edge. The turning angle was defined as the angle between the wing chord line and the direction of the deflected jet.

\section{RESULTS AND DISCUSSION}

In this section, the results of the various test configurations are discussed. These configurations involve changes in nozzle type, flap length, and flap angle. Velocity measurements at the exit plane of the nozzle, flap trailing edge, and downstream of the flap, are presented. A limited correlation of flap noise with some of the velocities is also made. Finally, a sumary comparison of the test configurations is presented. 
Nozzle and Flap Length Effects

The comparison of the slot nozzle and circular nozzle with deflector, as well as the comparison of the long and short flaps was obtained with the following test configurations: (1) slot nozzle and short flaps; (2) slot nozzle and long flaps; (3) circular nozzle and short flaps; and (4) circular nozzle and long flaps. A11 these configurations were tested at a flap angle of $40^{\circ}$ and will be compared for this flap setting.

Perceived noise. - The noise, on the basis of perceived noise level (PNL) for the four test configurations is compared in figure 8 . Here the maximum noise for a 500-foot flyover is plotted against exhaust jet velocity $V_{j}$. In all cases, the maximum noise occurred at $110^{\circ}$ from the inlet. At jet velocities between 600 and $800 \mathrm{ft} / \mathrm{sec}$, the range of most interest for current USB flap systems, flap length appears to be an important variable. The difference in changing from long to short flaps is an increase of about $4 \mathrm{PNdB}$. The effect of nozzle type is much smaller, generally about one $d B$ with the slot nozzle noisier. The relative insensitivity to nozzle type has also been seen in the small model tests of reference 3 .

The directivity of the four configurations for a 500-foot flyover at a high velocity typical of takeoff $(793 \mathrm{ft} / \mathrm{sec})$ is shown in figure 9 . Here again there is little difference between nozzles, while the flap length has a significant effect. All four configurations have a flyover directivity that is dominated by a large lobe of aft-radiated noise that peaks at $110^{\circ}$. For comparison, a directivity plot at a lower velocity (552 ft/sec) is also shown. Here the aft noise lobe is considerably smaller although it is still dominant. The rapid decrease in the aft quadrant noise with velocity is an Indication that the noise source dominating this quadrant is related to a higher power of velocity than the forward quadrant noise.

The 500-foot sideline PNL at an angle of $90^{\circ}$ from the inlet is shown in figure 10 as a function of altitude. All four nozzle-flap configurations show small changes in PNL with altitude up to 400 feet. The differences between configurations are also relatively small on a sideline when compared to a flyover. The short flaps showed a small peak at an altitude of 250 feet while the long flaps had a maximum value at zero feet. The trends shown here are the same at lower velocities.

Overall sound pressure. - While perceived noise level provides an indication of human annoyance, overall sound pressure level (OASPL) provides a better means of relating noise to other physical measurements. The four test configurations are compared in figure 11 on the basis of overall sound pressure level OASPL. Figure 11(a) shows the OASPL at 
$110^{\circ}$ from the inlet and $100-$ foot radius. The $110^{\circ}$ angle is of the most interest, since the flyover noise peaks here. The difference in OASPL between long and short flaps varies from 4 to $5 \mathrm{~dB}$. Once again, the effect of nozzle type is much smaller than flap length.

The dashed line in figure 11 (a) is a noise prediction for a USB flap system from reference 8 . The prediction is primarily based on sub-scale model data using relative flap lengths similar to the long flap tested here. As would be expected, the long flap data is closer to the prediction: The noise for the long flaps is progressively higher than predicted as the velocity increases. There is a significant difference in slope between the data and the prediction. The prediction is a sixth power function of velocity, while the full-scale data varies between the seventh and eighth power. The increase in noise above the prediction occurs only at angles aft of $90^{\circ}$. Figure $11(\mathrm{~b})$ shows the OASPL at an angle of $90^{\circ}$ from the inlet. At this angle both the test results and the prediction have a sixth power slope and the long flaps are only about one dB higher than the prediction. The agreement at $90^{\circ}$ and the increase in noise above the prediction at $110^{\circ}$ may be an indication of an additional noise source that becomes dominate at aft angles and high velocities. This noise source does not appear to any substantial degree in the small scale data that is the basis of the prediction. It also seems likely that the additional noise source is dependent on the eighth power of velocity.

Some insight into the major noise sources at play in the USB flap system can be gained by plotting the OASPL at various angles as a function of velocity. Figure 12 is such a plot for the slot nozzle and long flaps. In the flyover plane $\left(\phi=90^{\circ}\right)$ at angles from the inlet $\theta$ near $120^{\circ}$ the OASPL is a function of the seventh power of velocity, while at $\theta=90^{\circ}$ it is the sixth power and at $\theta=60^{\circ}$ it is the fifth power. The OASPL directly off the wing tip $\left(\phi=0, \theta=90^{\circ}\right)$ is also shown in the figure and is typical of noise at angles up to $40^{\circ}$ below the wing tip $\left(\phi<40^{\circ}\right)$. The change in slopes of these lines with direction is an indication of multiple noise sources. The slope in the aft quadrant (fig. 11(a)) is of the most interest since the noise peaks there. This slope varies between the seventh and elghth power of velocity depending on the test configuration. It seems likely that a combination of sixth and eighth power noise sources are at work here. USB flap noise has been thought to be primarily caused by dipole noise $\left(\mathrm{V}_{j}{ }^{6}\right)$ peaking $90^{\circ}$ from the deflected jet as indicated in reference 8 . This reference noted the existence in sub-scale tests of a region of quadrupole noise $20^{\circ}$ to $30^{\circ}$ from the deflected jet. The amount of quadrupole noise for the full-scale tests reported in this paper is considerably more thạ in previous sub-scale tests.

The noise radiation pattern below the wing in the flyover plane is shown in figure 13(a). Here OASPL at a 100-foot radius is plotted for all four nozzle-flap configurations. The data again fall into two bands, 
one for the long flaps and one for the short flaps. The short flaps are louder at all angles measured. All configurations have a noise peak near $120^{\circ}$ from the inlet or about $30^{\circ}$ from the deflected jet. The large lobes of noise centered at $\theta=120^{\circ}$ are not typical of previous sub-scale tests.

The noise radiation pattern between the wing tip and flyover directions is shown in figure 13(b). All the measurements shown in this flgure were made in a plane perpendicular to the engine axis $\left(\theta=90^{\circ}\right)$. Here again the data fall into two bands corresponding to the flap lengths. The short flaps show more noise directly below the wing than the long flaps. The increase in OASPL from the wing tip to the flyover direction corresponding to the long and short flaps is about $2 \mathrm{~dB}$ and $6 \mathrm{~dB}$, respectively. At small angles below the wing tip, there is little difference among any of the configurations.

Nolse spectra. - Sound pressure spectra for the four $40^{\circ}$ flap angle configurations are shown in figure 14. The spectra for the slot nozzle configurations in the flyover plane $\left(\phi=90^{\circ}\right)$ and at $\theta=110^{\circ}$ are shown in figure 14(a). Two velocity levels are shown here that bracket the range of most interest. The short flap has a spectral peak at $80 \mathrm{~Hz}$, while the long flap has a peak at $50 \mathrm{~Hz}$ and at a lower level. It is interesting to note here that the ratio of the wavelengths for the peak frequencies is the same as the ratio of the flow path lengths ( $L$ in fig. 5) for the two flaps. The largest differences in spectra for the long and short flaps is at low frequency. At the lower velocity, the short flap spectrum shows a double peak. Similar shape spectra have been seen in sub-scale tests (refs. 2 and 8 ). Figure 14 (b) shows the spectra for the circular nozzle and deflector configurations. The spectra here are almost identical to the corresponding spectra for the slot nozzle. As in the case of the slot nozzle, there is a shift in the spectral peak to lower frequencies with longer flaps.

A comparison of the spectra for the circular nozzle configurations with a spectrum as predicted from reference 9 , is shown in figure 14 (c), The comparison is made at $\theta=90^{\circ}$ and $\phi=90^{\circ}$ for a high velocity. Included for reference is the spectrum for the suppressed engine alone utilizing a circular nozzle. The predicted spectrum has a double peak with the lower frequency peak at $25 \mathrm{~Hz}$ and the higher frequency peak near $100 \mathrm{~Hz}$. The prediction is for flap geometry similar to the long flaps tested here. The measured long flap spectrum tends to parallel the prediction by staying a few $d B$ above it. The higher frequency peak of the prediction seems to correspond to the peak in the short flap spectrum and also a relatively small peak in the long flap case. Both flaps show decreasing levels below $50 \mathrm{~Hz}$ and don't demonstrate the $25 \mathrm{~Hz}$ peak of the prediction. A dramatic increase in low frequency noise can be seen by comparing the USB flap spectra to the engine alone spectrum. 
These high levels of very low frequency noise may cause a more serious problem with cabin interior noise than with community noise. At the higher frequencies the effect of wing shielding can be seen as the USB flap spectra approach the engine alone spectrum and finally cross below it.

\section{Effect of Flap Angle}

In order to determine the effect of flap angle on noise, three flap angles were tested using the short flaps and the slot nozzle. The three flap angles were $8^{\circ}$ (retracted flaps), $40^{\circ}$ (take-off) and $75^{\circ}$ (approach). Figure 15 shows both the maximum PNL on a 500-foot flyover and maximum OASPL at 100 -foot radius. While the $40^{\circ}$ flap appears to be the loudest on a 500-foot flyover (fig. 15(a)) the peak OASPL is about the same for both the $40^{\circ}$ and the $8^{\circ}$ flaps (fig. $15(\mathrm{~b})$ ). The difference shown in the flyover plot is a result of the directivity change between the two flap angles. The $75^{\circ}$ flaps were actually the quietest even on the basis of peak OASPL although only by $1.5 \mathrm{~dB}$. The flow path length from the nozzle exit to the flap trailing edge is longer for the $75^{\circ}$ flap than for the other two flap angles, as shown in figure 5(a). The peak velocity at the trailing edge is about 10 percent lower as will be shown later in this paper. This lower trailing edge velocity is a likely cause of the lower noise.

- The nolse radiation pattern below the wing in the flyover plane is shown in figure 16. The arrows in this figure represent the direction of the deflected jet. Both the $8^{\circ}$ and the $40^{\circ}$ flap angle show a peak OASPL about $30^{\circ}$ from the deflected jet and have radiation patterns of almost the same shape. The $75^{\circ}$ flap shows a peak closer to the deflected jet than the other flaps although, there is some uncertainty as to the exact location of the jet at this flap angle.

\section{Velocity Measurements}

In order to gain some insight into the important noise sources involved in the USB systems tested here and possibly to determine the controlling variables involved, extensive velocity surveys were made. Figure 7 shows the locations external to the engine where those velocity surveys were made.

Nozzle exit. - In order to determine the fully expanded exhaust jet velocity $v_{j}$ used in correlating the noise data the slot nozzle exit plane was surveyed. An example of the exit plane temperature and velocity 
contours are shown in figure 17. As seen in figure 17(a) the velocity is fairly uniform across the exit plane, with 90 percent of the flow area showing less than a 12 percent variation. It should be remembered here that these velocity contours were measured using a mixed-flow exhaust. The core stream total temperature before mixing was $1480^{\circ} \mathrm{R}$ for the example shown in figure $17(\mathrm{~b})$. The temperature contours show that the highest temperatures are near $800^{\circ} \mathrm{R}$. The 12 -lobe core mixer nozzle used here appears to be performing very well, even though the exhaust stream was forced into a rectangular shape as it was being mixed.

Flap trafling edge. - The velocity contours at the flap trailing edge for both nozzle types and both flap lengths are shown in figure 18 . All the contours shown here are for a flap angle of $40^{\circ}$. For each set of contours the peak trailing edge velocity $V_{\text {te }}$ is listed along with the average exhaust jet velocity $V_{j}$. Since the short flaps are part of a straight (no sweep or taper) wing, the flow was assumed symmetrical on either side of the engine centerline. Thus, the flow was probed only on one side of the centerline. For the long flaps, the flow was probed on both sides of the centerline since the wing here is both swept and tapered. Both long flap cases show more flow spreading and velocity decay than the corresponding short flap cases. The circular nozzle and deflector shows a tendency for the flow to leave the flap surface away from the centerline. This tendency is most noticeable with the short flap. Although these measurements were made primarily for the purpose of correlating the noise data, they may give an indication of the relative aerodynamic effectiveness of each system. This is especially helpful since no force measuring system was available for the wings at the time of these tests.

The velocity decay in terms of a plot of peak trailing edge velocity $V_{\text {te }}$ against $V_{j}$ is shown in figure 19. The peak trailing edge velocity, rather than an average or some other area weighted term, was used for convenience and simplicity. The largest velocity decays occurred with the long flap configurations. The circular nozzle and deflector also had the effect of increasing the decay. The velocity decay of the slot nozzle and short flap at $75^{\circ}$ is also shown on this plot. For $75^{\circ}$ the decay is 10 percent greater than the corresponding $40^{\circ}$ flap configuration. Part of this decay is due to an increase in path length (18 percent) from the $40^{\circ}$ to the $75^{\circ}$ flaps (fig. 5(a)).

Flow turning angle. - The large fixed survey rake shown in figure 7 was placed 10 feet downstream of the flap trafling edge for the purpose of determining the flow turning angle. This rake was used only at engine centerline height ( 9 feet above the ground). Thus, only the turning angle on the engine centerline was measured. Table II gives the resulting turning angles from the rake measurements. The $40^{\circ}$ flap configurations had turning angles near $30^{\circ}$. The $75^{\circ}$ flap had a turning angle of 
$70^{\circ}$ at the engine centerline. For the $75^{\circ}$ flap, it is believed that there is considerable difference in turning along the span of the wing. Time did not permit measuring the turning angle at other spanwise locations.

Correlation of Noise with Velocity

As a first attempt at correlating the data in this paper, $V_{\text {te }}$ was assumed the controlling parameter. The use of peak rather than some area-welghted velocity is not believed to make a major difference in the correlation of the data used here. The results of the above correlation are shown in figure 20 where the OASPL is plotted against $V_{\text {te }}$ for the four $40^{\circ}$ flap configurations tested. This type of plot does not collapse the data on one line. What was the quietest configuration on a plot using $v_{j}$ (fig. $1 l(a)$ ) is now shown as the noisiest. This overcorrection and the large amount of quadrupole noise at aft angles seen in the data. suggest that the noise is a combination of at least two separate sources. One source, the quadrupole, might be a function of $V_{j}$ to the eighth power and related to the impingement of the jet on the upper surface of the wing. This type of noise source has been called impact noise and investigated in reference 9. It was believed that the addition of this quadrupole noise to the dipole noise observed in sub-scale investigations should tend to collapse the data on to one line. It was assumed that the dipole source was related to $V_{\text {te }}$ to the sixth power and also that the two sources were uncorrelated.

The results of a correlation based on the addition of a source related to $V_{t e}{ }^{6}$ and one related to $v_{j}{ }^{8}$ are shown in figure 21 . The correlating parameter used is:

$$
\mathrm{f}\left(\mathrm{V}_{j}^{8}, \mathrm{~V}_{t \mathrm{t}^{6}}^{6}\right)=10 \log \left[10^{\left(\mathrm{K}_{j}+\log \mathrm{V}_{j}^{8}\right)}+10^{\left(\mathrm{K}_{\mathrm{te}}+\log \mathrm{V}_{\mathrm{te}} \mathrm{e}^{6}\right)}\right]
$$

Where $K_{j}=1.3$ for the short flap, and 0.954 for the long flap, and $\mathrm{K}_{\mathrm{te}}=6.93$ for all cases. The above expression represents the logarithmic addition of an eighth power and sixth power noise source. It was necessary to make a small change in the constant $K_{j}$ for the two flap lengths to get the data to collapse within $1.5 \mathrm{~dB}$. This increase in the level of the eighth power term might be due to the increase in deflector angle used with the short $f$ lap and/or a decrease in shielding effectiveness with decreasing flap length. The correlation was written for the $40^{\circ}$ flap angle data presented in this paper and in the form shown here 
cannot be expected to fit any other USB data. However, it should be fruitful to pursue the approach of multiple sources for the development of a more general correlation.

Summary Comparison of Test Configurations

Noise levels for all the configurations tested in this investigation are compared in Table III for two velocity levels. Exhaust jet velocities typical of takeoff $(760 \mathrm{ft} / \mathrm{sec})$, and approach $(600 \mathrm{ft} / \mathrm{sec})$ were chosen for this comparison. The maximum perceived noise level (PNL) for both a 500-foot flyover and on a 500-foot sideline at a 250 foot altitude are presented in the table. These noise levels are for a single engine with no forward velocity effect included. The fully suppressed engine alone and a representative under-the-wing blown flap configuration are also included for reference. Both the engine alone and the under-thewing configurations use the same exhaust system as the USB circular nozzle configuration (without the deflector plate). The swept wing with a triple-slotted flap system was used in the under-the-wing configuration. The location of the nozzle exit was at 8 percent of the wing chord. Some of the test results for this configuration are presented in reference 7 .

The maximum difference in PNL at takeoff among the $40^{\circ}$ flap configurations was $4.8 \mathrm{PNdB}$ for flyover. The corresponding maximum difference on the sideline was only 1.5 PNdB. Most of the increase in noise for the short flap configurations was directed below the wing and not off to the side. While the long flaps were significantly quieter than the short flaps, the circular nozzle and deflector was only slightly quieter than the slot nozzle. The small noise advantage for the circular nozzle may be offset by possible poorer aerodynamic performance as suggested by the velocity surveys at the flap trailing edge (fig. 18). The difference between flyover and sideline noise was over 5 PNdB for the short flap configuration and about $3 \mathrm{PNdB}$ for the long flap. The greater sideline relief for the short flap is for the most part a result of more noise in the flyover plane, not less on the sideline. At the lower $V_{j}$ values, most of the trends were the same with all the levels 6 to 9 PNdB lower. One exception was less sideline relief at the lower velocity.

The comparison of the test configurations with the engine alone (jet noise) shows an increase for flyover of 5 to $10 \mathrm{PNdB}$ due to the wing and flaps. The increase in noise for the USB systems on the sideline was 3 to $6 \mathrm{PNdB}$. The noisiest USB system tested was slightly quieter than the engine under-the-wing powered lift system included in Table III on both the flyover and sideline. 
CONCLUDING REMARKS

Flap chord length was shown to have a strong influence on noise for full-scale upper-surface-blown (USB) flap configurations used for powered lift. Noise increases associated with short flap length were primarily confined to the flyover plane. A short flap typical of current USB flap design was $4 \mathrm{~dB}$ noisier than a long flap design. The long flap had a flow path length almost 56 percent longer than the short flap. This longer path length resulted in greater velocity decay as indicated by measurements at the flap trailing edge. It is believed that the lower velocity for the long flap configurations is the major reason for the lower noise. However, greater shielding effectiveness may also contribute to the noise reduction.

The effect of velocity decay on noise implies that a decayer-type nozzle or deflector, could be employed to reduce the system noise. The spectral shift of jet noise to higher frequencies associated with decayers is an advantage for a USB system since, higher frequencies are more effectively shielded by the wing.

A slot nozzle with a $4: 1$ aspect ratio was shown to have no more advantage over a circular nozzle with a deflector. However, the slot nozzle appeared to provide somewhat better flow attachment to the flap.

The data obtained from this investigation suggest the presence of at least two important noise sources, one a dipole $\left(V^{E}\right)$ and the other a quadrupole $\left(V^{8}\right)$. Substantially more quadrupole noise in the region near the deflected jet was observed than in sub-scale tests. The reason for this quadrupole noise increase above the sub-scale results is not known. It is belleved that the quadrupole noise might be a result of the impingement and interaction of the jet with the wing surface in the vicinity of the nozzle (i.e. impact noise). Further investigation of the quadrupole source present in large USB systems may lead to noise reductions.

\section{REFERENCES}

1. M. Reshotko, J. H. Goodykoontz, and R. G. Dorsch, "Engine-Over-theWing Noise Research," AIAA paper no. 73-631, Fluid and Plasma Dynamics Conference, 6th, Palm Springs, July 1973.

2. R. G. Dorsch, "Externally Blown Flap Noise Research," SAE paper no. 740468, National Air Transportation Meeting, Dallas, April-May $19.74 \ldots$ 
3. R. G. Dorsch, M. Reshotko, and W. A. Olsen, "Flap Noise Measurements for STOL Configurations Using External Upper Surface Blowing," AIAA paper no. 72-1203, Joint Propulsion Specialist Conference, 8th, New Orleans, November-December 1972.

4. N. E. Samanich, L. J. Heidelberg, and W. L. Jones, "Effect of Exhaust Nozzle Configuration on Aerodynamic and Acoustic Performance of an Externally Blown Flap System with a Quiet 6:1 Bypass Ratio Engine," AIAA paper no. 73-1217, Propulsion Conference, 9th, Las Vegas, Nov. 1973.

5. W. L. Jones and L. J. Heidelberg, "Investigation of Noise from FullScale High Bypass Engine and Blown Flap System," SAE paper no. 740467, National Air Transportation Meeting, Dallas, April-May 1974.

6. M. D. Falarski, K. Aoyagi, and D. G. Koenig, "Acoustic Characteristics of a Large-Scale Wind-Tunnel Model of an Upper-Surface Blown Flap Transport Having Two Engines," NASA TM X-62319, September 1973.

7. W. L. Jones, L. J. Heidelberg, and R. G. Goldman, "Highly Noise Suppressed Bypass 6 Engine for STOL Application," AIAA paper no. 73-1031, Aero-Acoustics Conference, Seattle, October 1973.

8. R. G. Dorsch, B. J. Clark, and M. Reshotko, "Interim Prediction Method for Externally Blown Flap Noise," NASA TMX (to be published).

9. D. J. McKinzie, Jr., and R. J. Burns, "Analysis of Noise Produced by Jet Impingement Near the Trafling Edge of a Flat and a Curved Plate," NASA TM X-3171, January 1975. 
TABLE I. - TE 34 ENGINE PERFORMANCE AT MAXIMUM POWER CORRECTED TO SEA-LEVEL-STATIC, STANDARD DAY

\begin{tabular}{|l|c|c|}
\hline & $\begin{array}{c}\text { UNSUPPRESSED } \\
\text { ENGINE } \\
\text { SEPARATE FLOW }\end{array}$ & $\begin{array}{c}\text { SUPPRESSED } \\
\text { ENGINE } \\
\text { MIXED FLOW }\end{array}$ \\
\hline THRUST, LB & 9200 & 8250 \\
FAN SPEED, RPM & 6800 & 6780 \\
HIGH PRESS. TURB, DIST. TEMP., ${ }^{\mathrm{R}}$ & 1955 & 1955 \\
FAN PRESSURE RATIO & 1.48 & 1.48 \\
BYPASS RATIO & 6.7 & 6.5 \\
TOTAL AIR FLOW, LB/SEC & 332 & 317 \\
\hline
\end{tabular}

TABLE II. - TURNING ANGLE ON ENGINE CENTERLINE FOR USB FLAP TEST CONEIGURATIONS

\begin{tabular}{|c|l|c|c|}
\hline \multirow{2}{*}{ NOZZLE } & FLAP & $\begin{array}{c}\text { FLAP ANGLE, } \\
\delta_{\mathrm{f}}, \mathrm{DEG} .\end{array}$ & $\begin{array}{c}\text { TURNING ANGLE, } \\
\delta_{j}, \text { DEG. }\end{array}$ \\
\hline & & & 6 \\
SLOT & SHORT & 8 & 28 \\
SLOT & SHORT & 40 & 25 \\
SLOT & LONG & 40 & 29 \\
CIRCULAR & SHORT & 40 & 30 \\
CIRCULAR & LONG & 40 & 70 \\
SLOT & SHORT & 75 & \\
\hline
\end{tabular}


TABLE III. - NOISE COMPARISON OF USB FLAP CONFIGURATIONS UTILIZING A SUPPRESSED TF 34 ENGINE

SINGLE ENGINE, NO FORWARD VELOCITY, NOZZLE EXIT $=7.0 \mathrm{FT}^{2}$

\begin{tabular}{|c|c|c|c|c|c|c|}
\hline \multirow{2}{*}{\multicolumn{2}{|c|}{ CONF IGURATION }} & \multirow{3}{*}{$\begin{array}{l}\text { FLAP } \\
\text { ANGLE, } \\
\text { DEG. }\end{array}$} & \multicolumn{2}{|c|}{$v_{j}=760 \mathrm{FT} / \mathrm{SEC}(\mathrm{TAKEOFF})$} & \multicolumn{2}{|c|}{$\mathrm{V}_{\mathrm{j}}=600 \mathrm{FT} / \mathrm{SEC}$ (APPROACH) } \\
\hline & & & \multirow{2}{*}{$\begin{array}{l}\text { MAX. PNL FOR A } \\
\text { 500-FT FLYOVER, } \\
\text { PNdB }\end{array}$} & \multirow{2}{*}{$\begin{array}{c}\text { MAX. PNL ON A } \\
\text { 500-FT SIDELINE, } \\
\text { PNdB }\end{array}$} & \multirow{2}{*}{$\begin{array}{l}\text { MAX. PNL FOR A } \\
500 \text { - FT FLYOVER, } \\
\text { PNAB }\end{array}$} & \multirow{2}{*}{$\begin{array}{c}\text { MAX. PNL ON A } \\
\text { 500-FT SIDELINE, } \\
\text { PNdB }\end{array}$} \\
\hline FLAP & NOZZLE & & & & & \\
\hline LONG & SLOT & 40 & 99.0 & 95.8 & 90.8 & 90.0 \\
\hline LONG & CIRCULAR & 40 & 98.0 & 95.0 & 89.3 & 88.0 \\
\hline SHORT & SLOT & 40 & 102.8 & 97.3 & 94.8 & 90.5 \\
\hline SHORT & CIRCULAR & 40 & 101.8 & 96.0 & 93.0 & 88.5 \\
\hline SHORT & SLOT & 8 & 100.8 & 97.0 & 93.2 & 90.0 \\
\hline SHORT & SLOT & 75 & 99.5 & 96.5 & 92.0 & 90.0 \\
\hline & ALONE & -- & 93.0 & 92.0 & 85.0 & 84.0 \\
\hline ENGINE & R-THE-WING & 40 & 103.0 & 99.0 & 95.2 & 90.8 \\
\hline
\end{tabular}




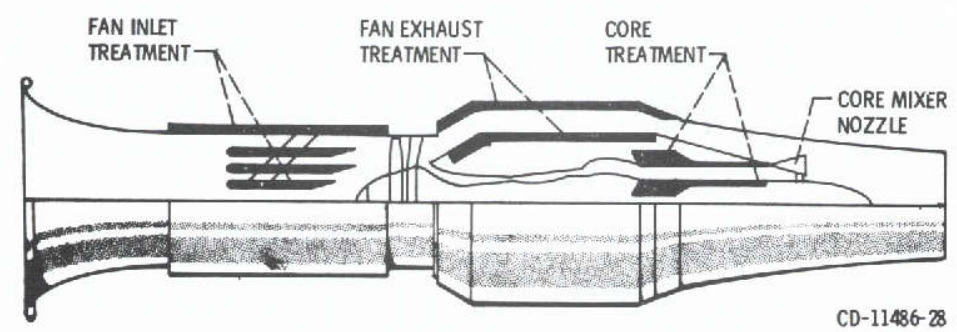

Figure 1. - Acoustically treated TF34 engine with mixed flow exhaust and circular nozzle.

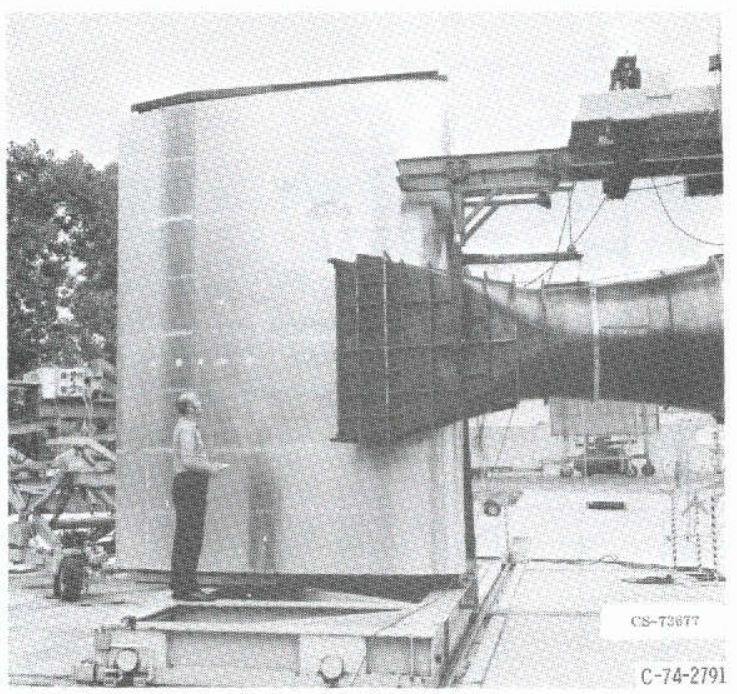

(a) SLOT NOZZLE, ASPECT RATIO, 4:1.
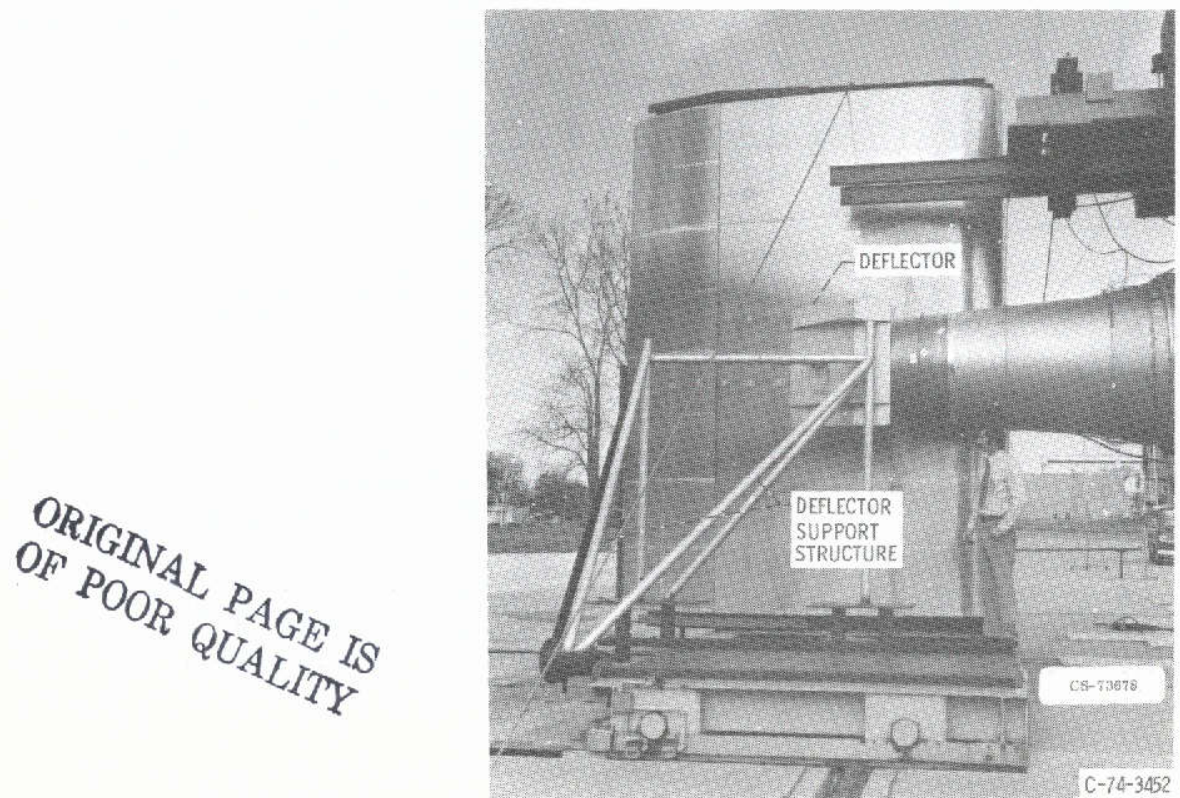

(b) CIRCULAR NOZZLE AND DEFLECTOR,

Figure 2. - Test nozzles with unswept wing. 


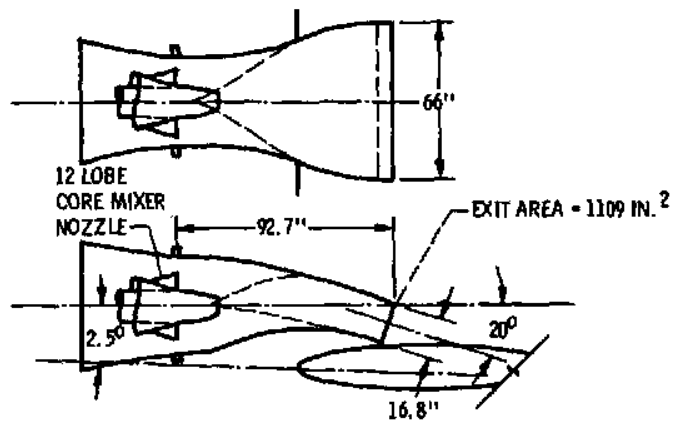

Fiqure 3. - Slot nozzle ddimenslons in in. . .

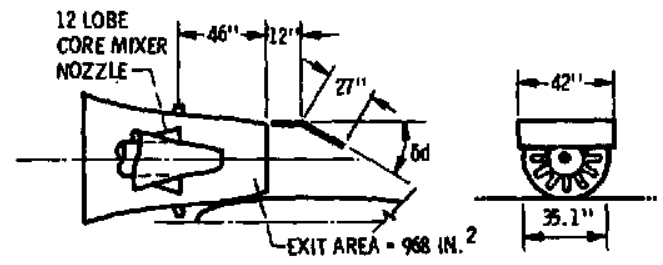

Figure 4. - Clrcular nozzle and deflector vilimensions in in.).
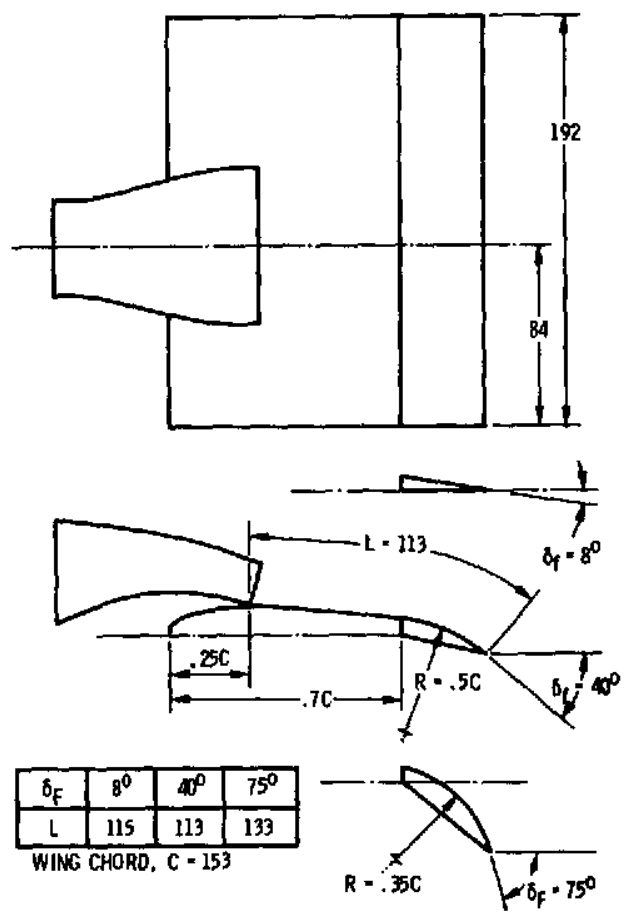

(a) UNSWEPT WING WITH SHORT FLAPS; OIMENSIONS IN IN. .
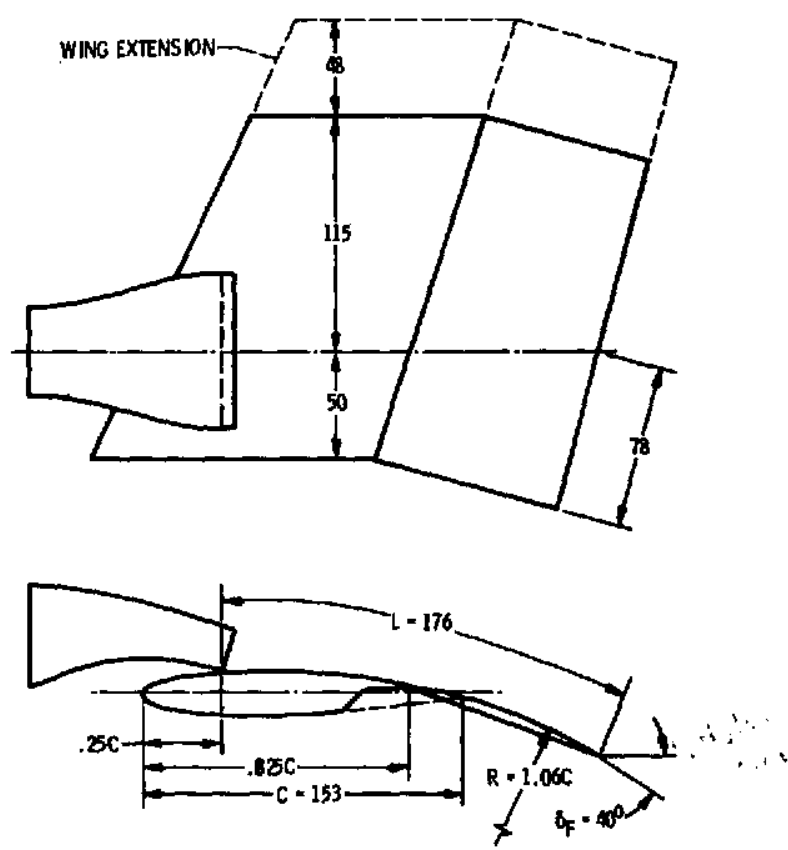

D) SWEPT WING WTH LONG FLAP (DIMENSIONS IN IN.).

Flgure 5. - Test wing and flap systems. 

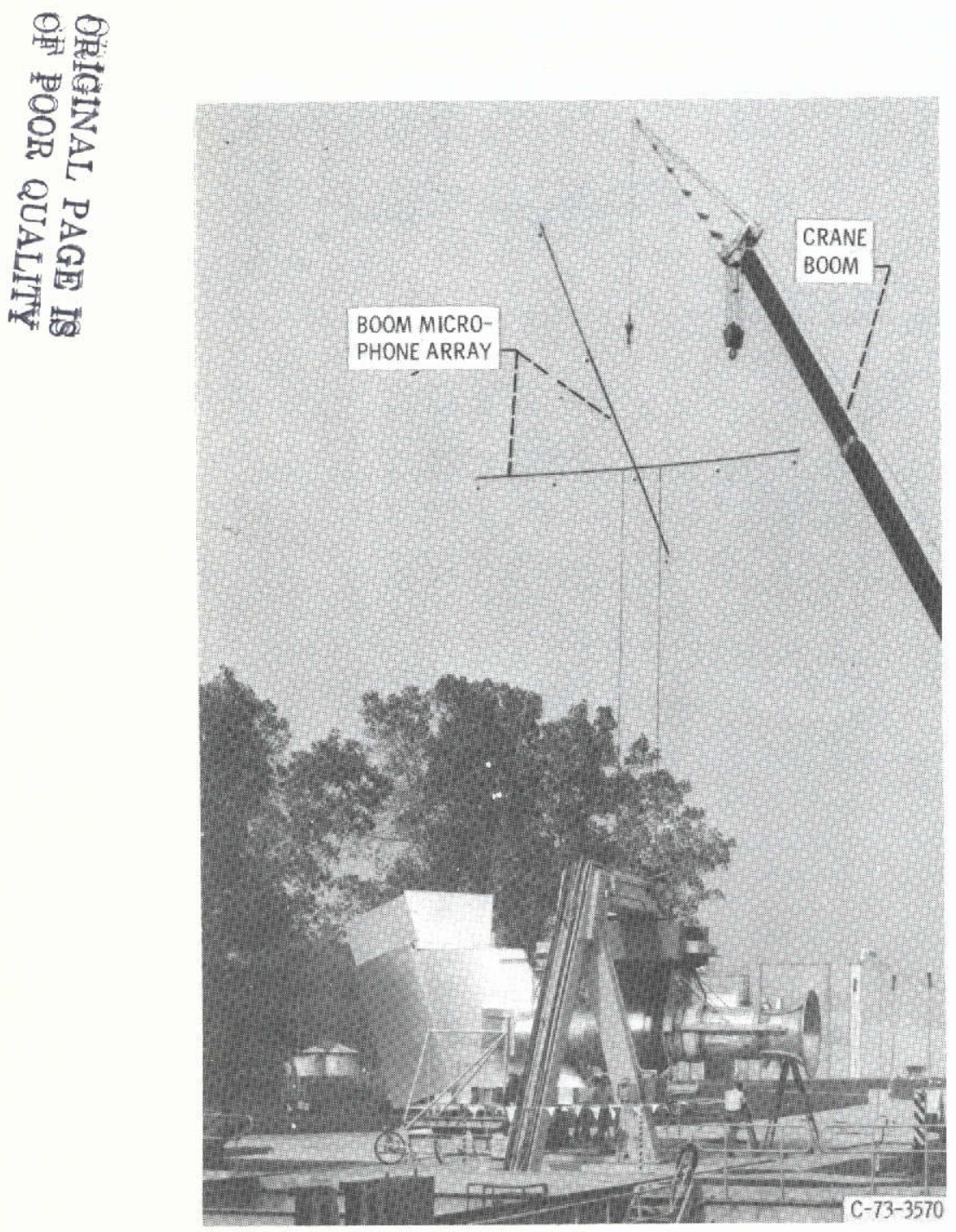

Figure 6. - Test installation showing boom microphone array used for sideline noise measurements.

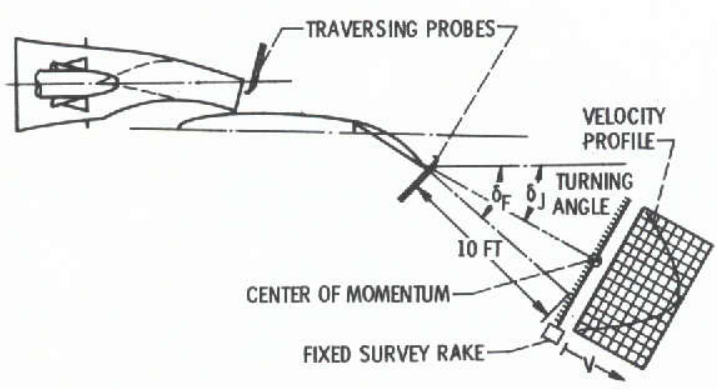

Figure 7. - Plan vlew of nozzle and wing showing location of velocity surveys.

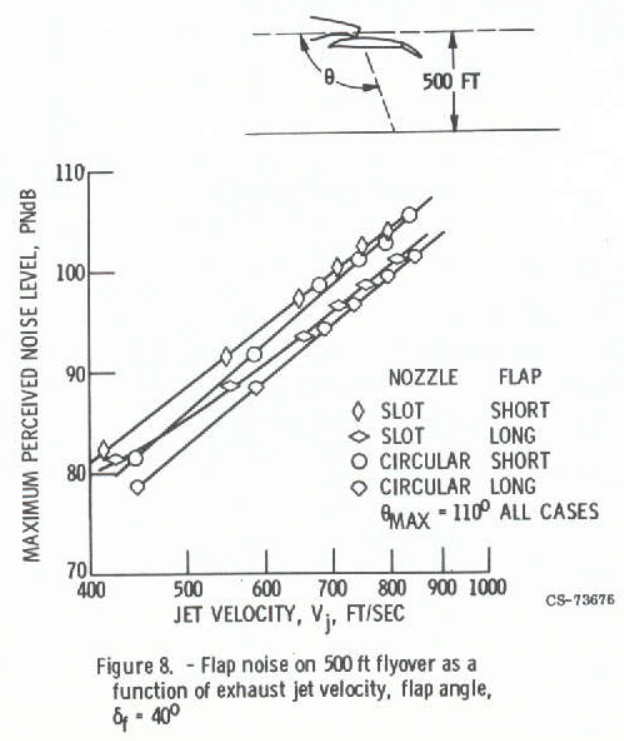




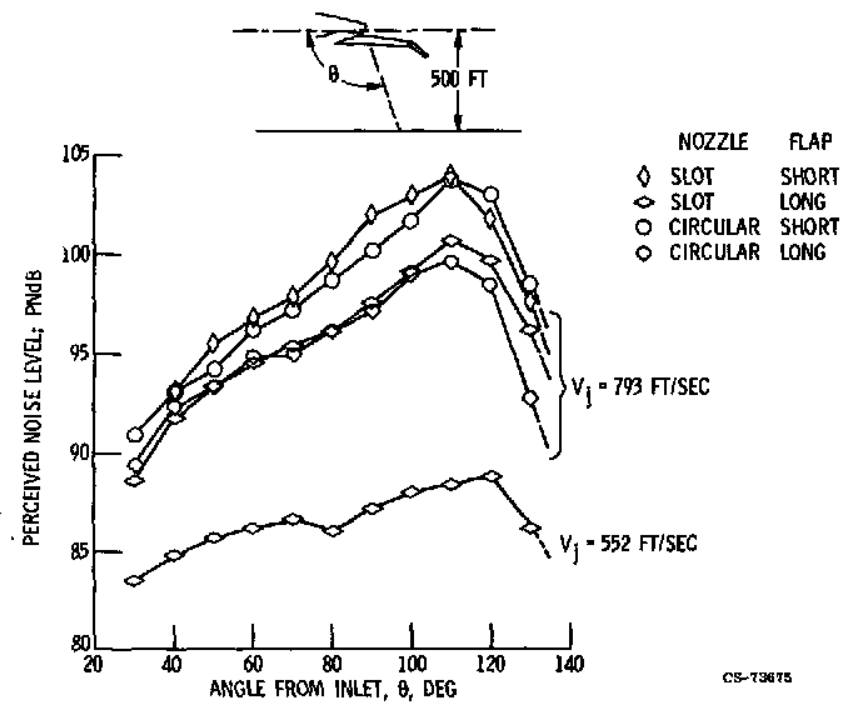

Figure 9. - Noise directivity for a $500 \mathrm{ft}$ flyover.
$\hat{\sigma}_{4}=40^{\circ}$.
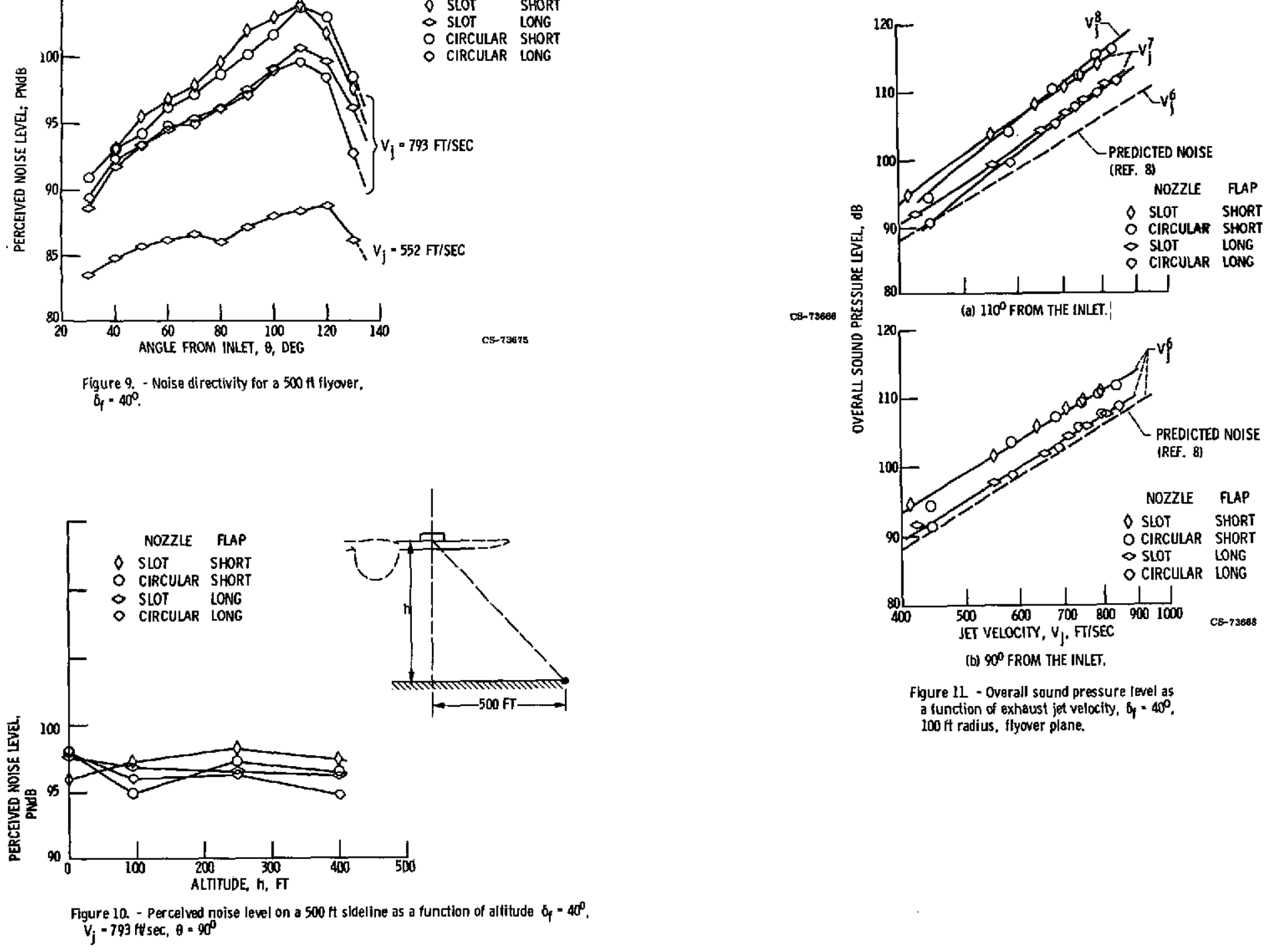

Figure 11 - Overall sound pressure level as a function of exhaust jet velocity, $b_{f}=40^{\circ}$. 100 it radius, flyover plane. 


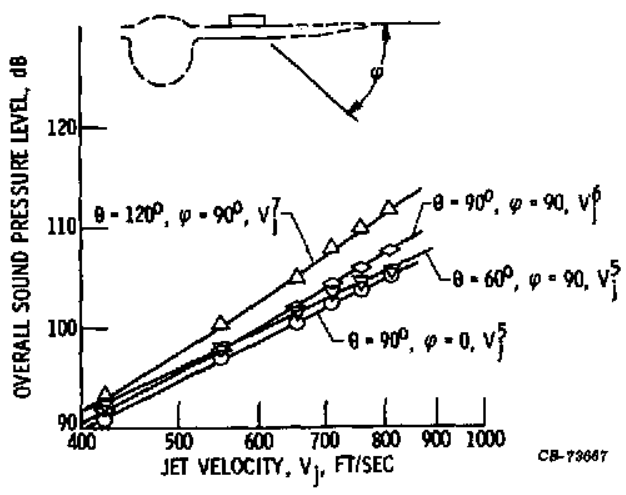

Figure 12 - Overall sound pressure level in various directions as a functlon of jet ve-

locity. IIOO it radius, configuration: siot

nozzle, long flap, $\sigma_{f} \cdot 40^{0}$.

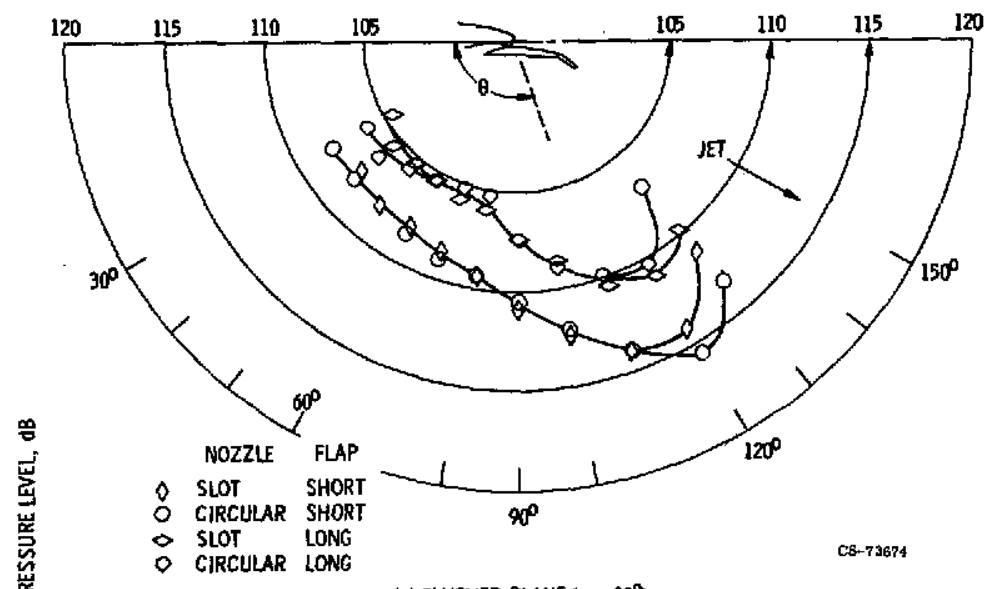

(a) FLYOVER PLANE $(\varphi=909$.

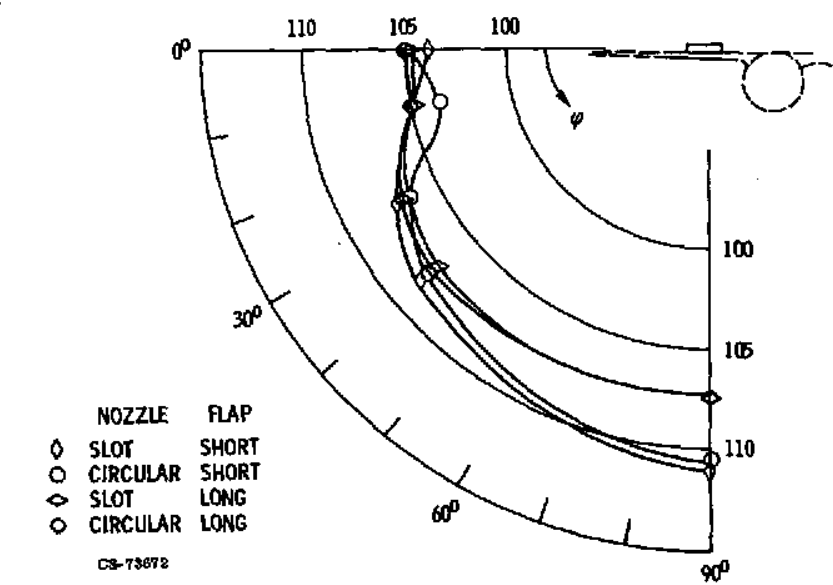

(b)-PLANE PERPENDICULAR TO ENGINE.AXIS $(\theta=9009$

Figure 13. - Noise radiation patterns for $40^{\circ}$ flap angle at $100 \mathrm{ft}$ radius. $N_{j}=793 \mathrm{ftsec}$. 

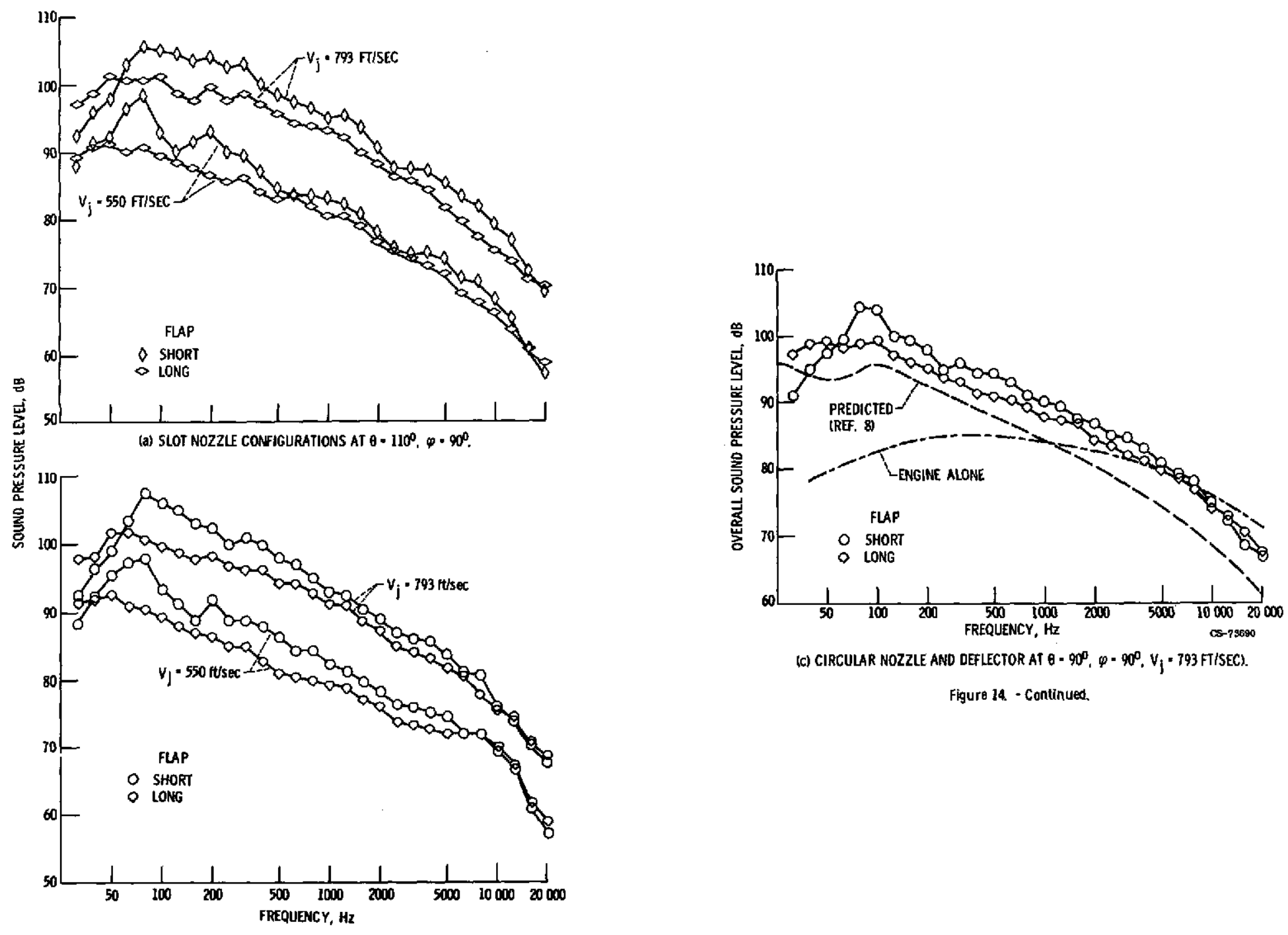

Figure 14. Continued.

(D) CIRCULAR NOZZIF AND DEFLECTOR CONFIGURATIONS AT $\theta=110^{\circ} . \varphi$ - $0^{\circ}$. Figure 14. Comparison of sound pressure level spectra at a $40^{\circ}$ flap angle. (100 ft radius). 

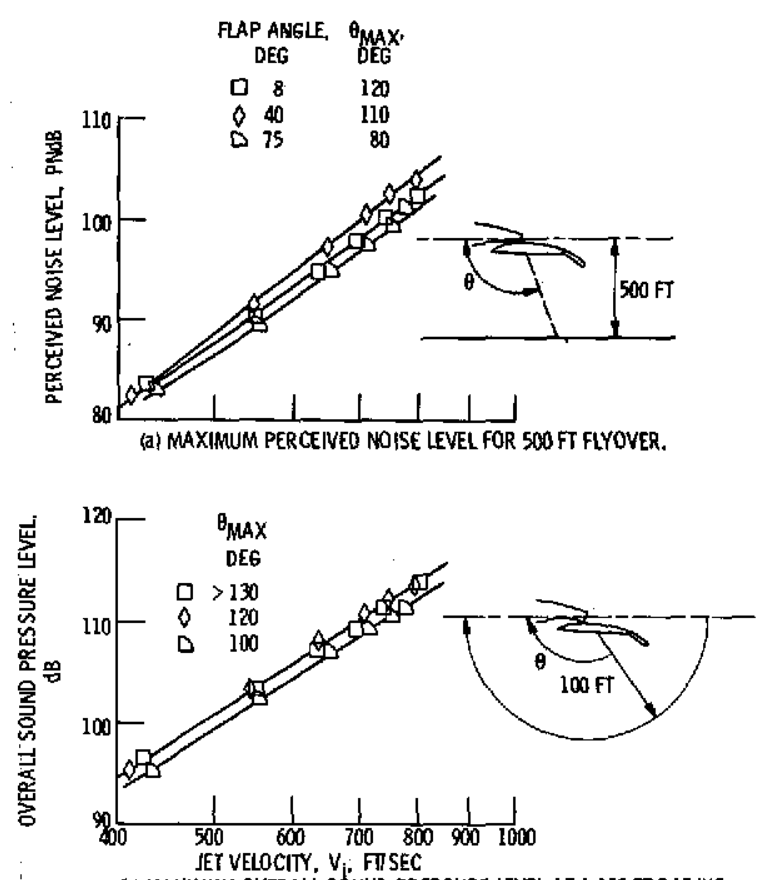

(b) MAXIMUM OVERALL SOUND PRESSURE LEVEL ATA 100 FT RADIUS.

Figure 15. - Noise for various flap angles as a function of jet velocity. (Configuration: slof nozzle, short flaps.).

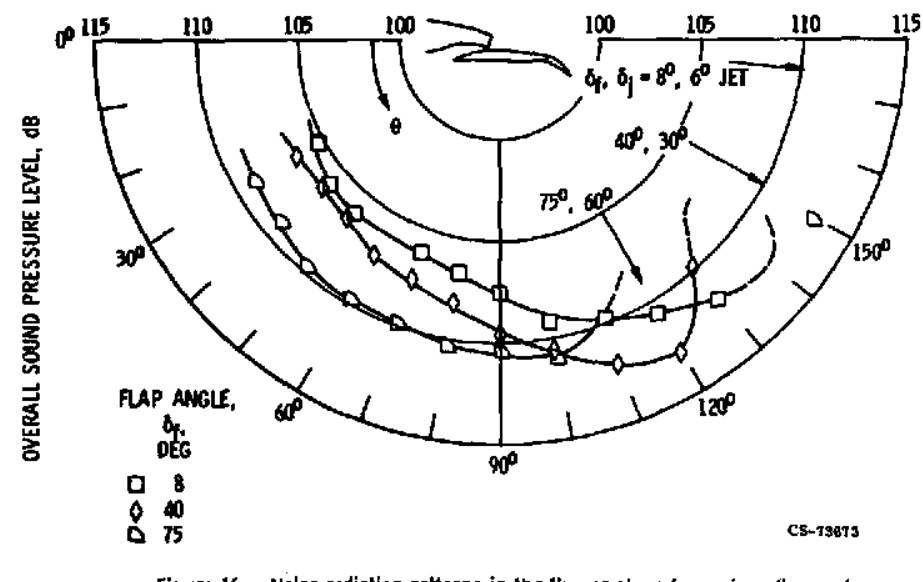

Figure 16. - Nolse radiation patterns in the llyover plane for various flap angles, $V \cdot 795 \mathrm{ft} / \mathrm{sec}, 100 \mathrm{ft}$ radius, conflguration: slot nozzle, short flaps.

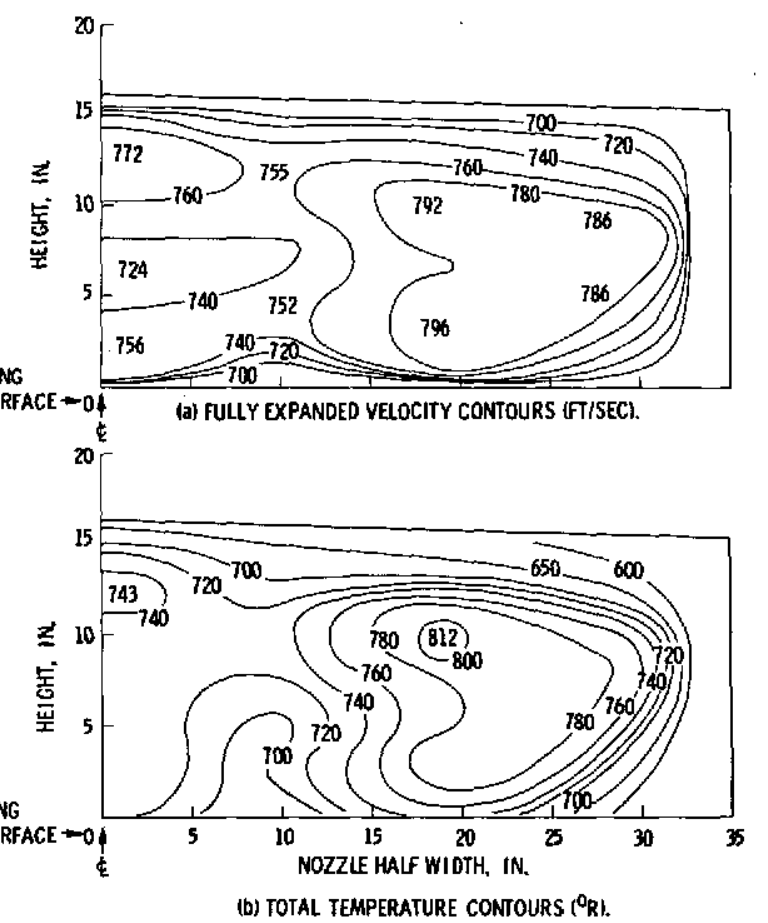

Figure 17. - Flow survey at exit plane of slot nozzle. $\left(V_{j}-788 \mathrm{tt} / \mathrm{sec}\right.$, 


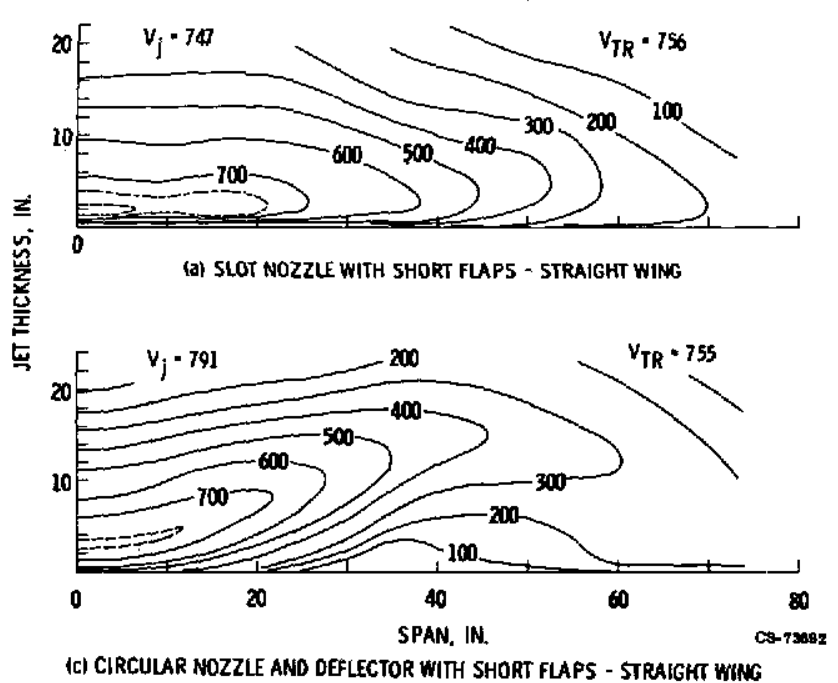

Figure 18 - Trailing edge velocity contours for various nozzle

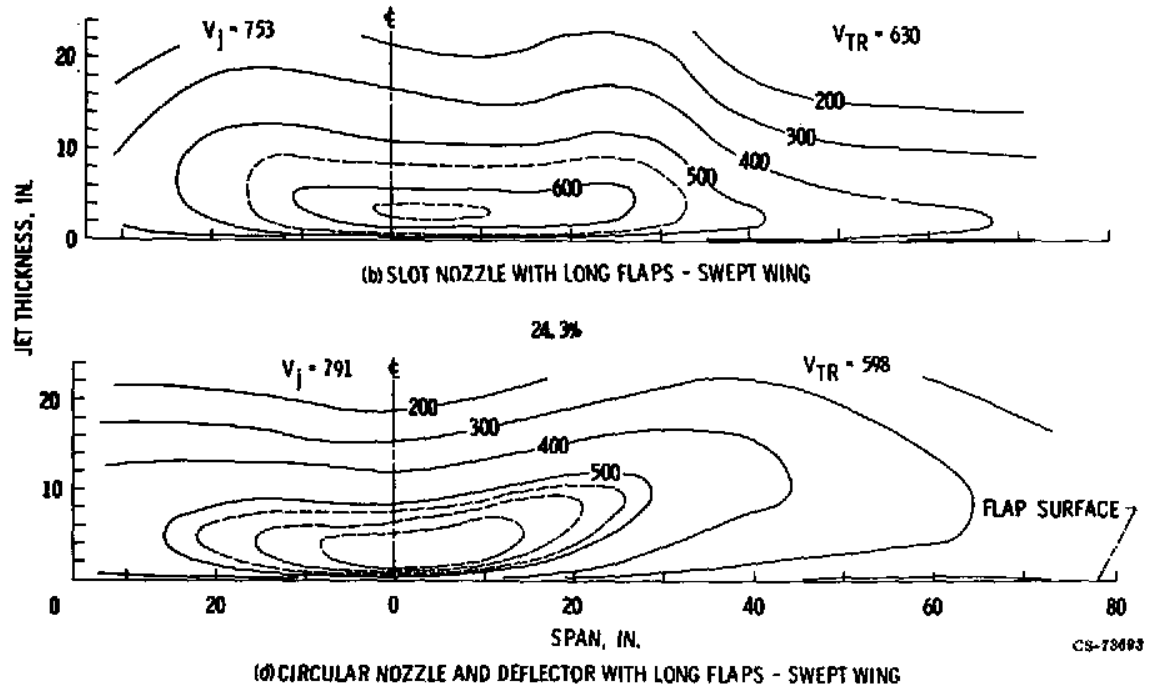

and flap configurations, $140^{\circ}$ falp angle, velocity in $\mathrm{ft} / \mathrm{sec}$. 


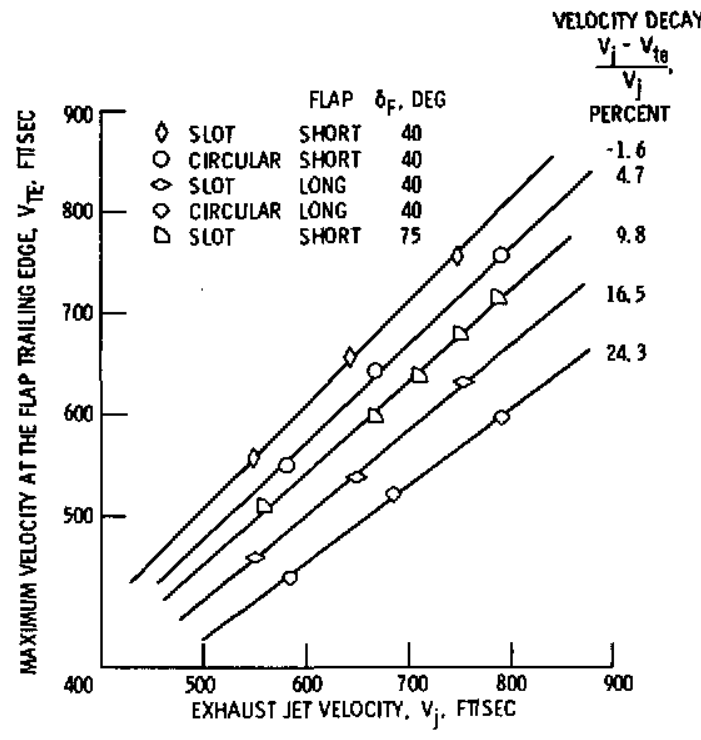

Figure 19. - Maximum trailing edge velocity as a function of exhaust jet velocity.

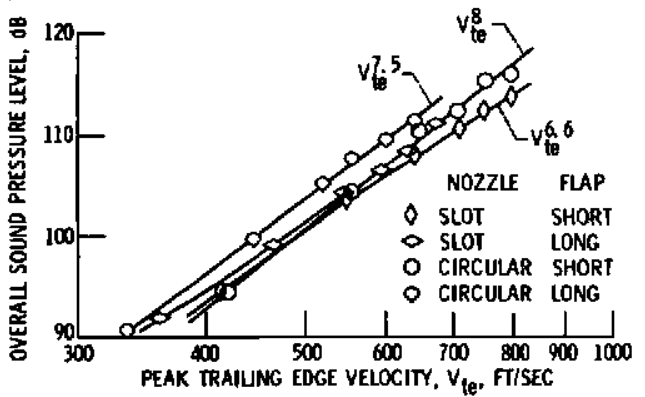

Cs-7.3670 Figure 20 - Noise comparison on the basis of tralling edge velocity. $\left(\theta \cdot 110^{\circ}, 100\right.$ il radius $)$.

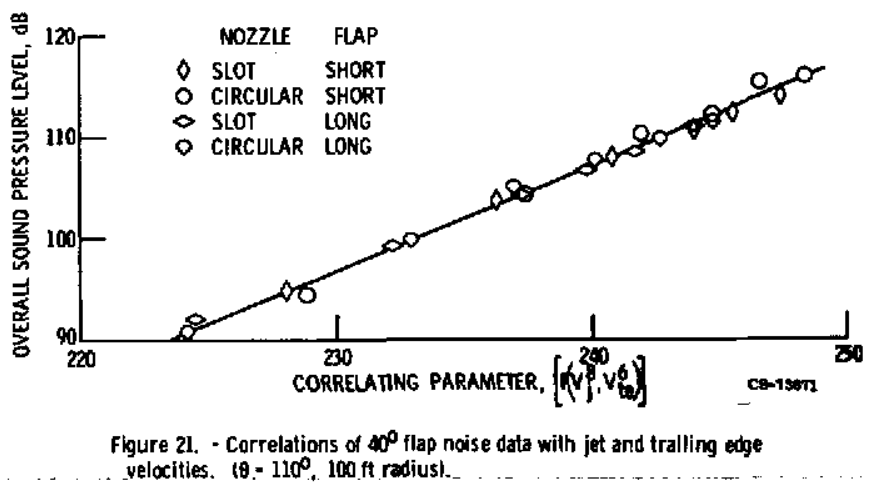

